\title{
The Differential Analysis on Intensive Use Efficiency of Construction Land
}

\author{
Xin Luo \\ College of Economics and Management, Sichuan Agricultural University \\ Chengdu 611130, China \\ Tel: 86-136-6811-0926_E-mail: jellyluoxin@hotmail.com \\ Jianqiang Li (Corresponding author) \\ College of Economics and Management, Sichuan Agricultural University \\ Chengdu 611130, China \\ Tel: 86-139-8161-6343Ｅ-mail: ljq9801@163.com
}

Wei Sun

College of Economics and Management, Sichuan Agricultural University

Chengdu 611130, China

Tel: 86-135-4111-7014Ｅ-mail: seaersun@hotmail.com

Received: January 6, 2012 Accepted: January 29, 2011 Online Published: April 17, 2012

doi:10.5539/jas.v4n6p19

URL: http://dx.doi.org/10.5539/jas.v4n6p19

\begin{abstract}
Land is the base of survival and development of human being. Limited land resource is the power that stimulates us to intensively use land. According to the connotation of intensive use of construction land, we select 5 indices which are cogent and effective. Then through Data Envelopment Analysis(DEA), we estimate the different efficiency of intensive use of construction land in China and its 31 provincial regions. The result is that in these 31 regions, only Heilongjiang and Shanghai are efficient, and the other DMUs are inefficient. At last, based on this result, we provide some relevant advices.
\end{abstract}

Keywords: Data envelopment analysis, Construction land, Intensive use efficiency, Differencial analysis

\section{Introduction}

Land, as one of primary natural resources, is a necessary material basis of human production and a essential carrier of other natural resources (WANG Wanmao, 2002). In China, the population is so large, which causes the per capita land resource too scarce. In the meantime, China is in the period of rapid industrialization and urbanization. So the conflict between supply and demand of construction land is extremely obvious.

In recent years, many scholars have estimated the intensive use efficiency of construction land from different aspects through different methods. But these methods have been mostly influenced by the subjectivity of index selection, dimensionless method, and weight choice, which makes the results not objective. Compared with traditional methods, Data Envelopment Analysis (DEA) provides convenience to the efficiency measure of decision making unit. In the existing research literatures, DEA has been used in many areas, such as urban efficiency (LI Xun et al., 2005), urban land use (SONG Ge et al., 2008), and urban land use efficiency(TIAN Chun\&LI Shiping, 2009; LI Chunhua et al., 2011). However, the differential analysis of estimating intensive use efficiency of construction land through DEA is rare. Therefore, in this paper, we analyze on intensive use efficiency of construction land in China and its 31 provincial regions from 1999 to 2008, by DEA method and DEAP2.1 software. 


\section{Method}

Data envelopment analysis (DEA) is a non-parametric model, which is used to estimate the decision making units (DMU) that has more than one input or output. This model was originally created by Farrel (Farrel, 1957) who made the use of mathematical programming to get the efficiency frontier. After then, according to the model, Charnes, Cooper, and Rhodes (Charnes A. et al., 1978) proposed CCR model which improved the efficiency measure of one single output to that of multi outputs. In 1984, Banker, Charns, and Cooper (Banker R.D. et al., 1984) promoted CCR model to BBC model with adding the variability of DMU's production scale. In this time, the model could evaluate pure technological efficiency (PTE) and scale efficiency (SE) besides estimating the technological efficiency (TE). TE=PTE $\times$ SE. Additionally, after DEA firstly came to China in 1988 , the method has been domestically popular and applied (LI Xun et al., 2005).

Now DEA is an important and effective method in many fields. Based on mathematical programming model, it estimates relative efficiency of DMU's input and output by effective data (WEI Quanling, 2006). Compared with traditional statistical methods, DEA mainly has 3 advantages. First of all, on the basis of sample data, DEA is practiced for analyzing on relative effective individual sample. Secondly, DEA model cannot be influenced by dimensionless method of input-output data. Thirdly, it does not need to pro-calculate the input-output production function (ZHANG Weili et al., 2005). Therefore, by Fare's method (Fare R S, 1994) we structure an effective frontier as a provincial region as a DMU in order to rate the construction land efficiency of each region. The DEA efficiency score of DMUs that are just on the effective frontier is equal to 1 . The others are inefficient. And their technological efficiency score is in the internal of $(0,1)$.

\section{Model Construction and Solution}

\subsection{Indices Selection and Data Sources}

Intensive use of construction land is reasonably increasing the input of capital and labor input in each unit of construction land, which is in the order to improve the revenue. Thus, the intensive use efficiency of construction land could be evaluated by the ratio of input and output in each unit of construction land. According to this connotation, we choose 3 indices as input indices, such as the number of employed persons of secondary industry in each unit of construction land, the number of employed persons of tertiary industry in each unit of construction land, and the non-agricultural fixed assets investment in each unit of construction land. Also, we choose the output value of secondary industry in a unit of construction land and the output value of tertiary industry in a unit of construction land as output indices.

In this paper, all original data are from "China Statistical Yearbook" and "China Land and Resources Almanac". But here we must note that: firstly, because the numbers of employed persons of the secondary and tertiary industry in 2006 lacked in "China Statistical Yearbook", so we substitute the arithmetic mean of those in 2005 and 2007 for that in 2006; additionally, non-agricultural fixed assets investment = total investment - (agriculture investment + forestry investment + animal husbandry and fishery investment); lastly, in order to avoid inflation, non-agricultural fixed assets investment and output value of the secondary and tertiary industry in every year are calculated on the basis of the data in 1999. For example, non-agricultural fixed assets investment in $2001=$ non-agricultural fixed assets investment on "China Statistical Yearbook" $\times 104 \div$ (price index of $2001 \times$ price index of 2000).

\subsection{Results and Analysis}

Figure 1 provides the variation of national total TE, PTE, SE from 1999 to 2008. In this picture, the national total TE and PTE of the 10 years are relatively unstable excluding SE. What is more, arithmetic mean of TE, PTE, and SE of intensive use of construction land during the 10 years are respectively equal to $0.768,0.781$, and 0.984 . Notably, the arithmetic mean of PTE is much lower than that of SE. It indicates that the inefficiency of intensive use of Chinese construction land is mainly due to the inefficiency of PTE. Thus, to raise the PTE of intensive use of urban land is the key to enhance the overall efficiency of intensive use of Chinese urban land and the efficiency of land intensive use.

\subsubsection{Technological Efficiency Analysis}

Technological efficiency is the overall efficiency of DEA model. Through DEAP2.1 software, we evaluate the technological efficiency (TE), pure technological efficiency (PTE), and scale efficiency (SE) of each provincial region from 1999 to 2008.

In Table 1 , the average TE score of china during the 10 years is 0.768 , which is not high and hints technological efficiency of intensive use of Chinese construction land should be improved. From 1999 to 2008, there are 17 provincial regions in which the arithmetic means of TE are higher than that of national total, such as Beijing, 
Tianjing, Hebei, Shanxi, Liaoning, Heilongjiang, Shanghai, Jiangsu, Zhejiang, Fujiang, Shandong, Henan, Hubei, Hunan, Guangdong, Hainan, Xinjiang. On the other hand, the average TEs of the others, Inner Mongolia, Jilin, Anhui, Jiangxi, Guangxi, Chongqing, Sichuan, Guizhou, Yunnan, Tibet, Shaanxi, Gansu, Qinghai, Ningxia, are lower than that of national total. Moreover, only TEs of Heilongjiang and Shanghai are equal to 1 and effective over 10 years. And Ningxia is the unique provincial region that has the lowest average TE.

Additionally, the difference of TE in each region is very apparent. Thus, in order to analyze more deeply we divide the 29 provincial regions that have not been effective during the 10 years into 3 groups: the first group contains the regions where the arithmetic mean of TE is between 0.4 to 0.6 , which are Ningxia, Qinghai, and Guizhou; the second group contains the regions in which the arithmetic mean of TE is between 0.6 to 0.8 , which are Hebei, Shanxi, Inner Mongolia, Jilin, Zhejiang, Anhui, Jiangxi, Henan, Guangxi, Chongqing, Sichuan, Yunnan, Tibet, Shaanxi, Gansu; the third group contains the regions that has the arithmetic mean of TE is between 0.8 to 1.0, which are Beijing, Tianjing, Liaoning, Jiangsu, Fujiang, Shandong, Hubei, Hunan, Guangdong, Hainan, Xinjiang. To sum up, the first group involves 3 regions; the second one includes 15 regions; and the third one has 11 regions. Obviously, the average DEA scores of most provincial regions are in the internal of $(0.6,0.8)$. Furthermore, most regions among the regions where the average TEs are relative higher locate in the eastern economy developed area. By contrast, most provincial regions among the regions in which the average TEs are relative lower locate in the mid-western economy underdeveloped area.

\subsubsection{Pure Technological Efficiency Analysis}

Table 2 summarizes the PTEs of intensive use of construction land in China and each provincial region. As a result, the arithmetic mean of PTE of national total is equal to 0.781 . Among these 31 provincial regions, the PTEs of only Heilongiiang, Shanghai, and Xinjiang are 1 and effective over the 10 years. Excluding them, the regions where PTEs are lower than that of national total contains Jiangxi, Chongqing, Sichuan, Guizhou, Yunnan, Shaanxi, Ningxia. The other 21 provincial regions have higher PTEs than national total level. It implies that even though the PTEs of intensive use of construction land in most provincial regions are higher than that of national total, the whole PTE level in China is still low.

For the 10 years of data, the PTE of intensive use of construction land in each provincial region is quite different. In 28 inefficient regions, Hainan has the highest PTE score, because it is not effective just in 2008. By contrast, the region in which the average PTE score is the lowest is Guizhou. Similarly we divide these regions into 3 groups. The first group contains regions where the arithmetic mean of PTE is lower than 0.7. They are Chongqing, Sichuan, Guizhou, Shaanxi, Ningxia. In addition, the second group contains regions where the arithmetic mean of PTE is in the internal of $(0.7,0.9)$. They are Hebei, Shanxi, Liaoning, Jilin, Zhejiang, Shandong, Hubei, Hunan, Guangxi, Tibet, Anhui, Jiangxi, Henan, Yunnan. Ultimately, the third group contains the rest 9 regions in which the arithmetic mean of PTE is higher than 0.9. In a word, most regions among the regions in which the average PTEs are relative higher locates in the eastern economy developed area. Whereas, most provincial regions among the regions in which the average TEs are relative lower locates in mid-western the economy underdeveloped area.

\subsubsection{Scale Efficiency Analysis}

The SEs of intensive use of construction land in China and each provincial region are listed in Table 3. From 1999 to 2008, the average SE score of national total is 0.984 , which is much higher than the average PTE value. In 31 provincial regions, only Heilongjiang and Shanghai have been effective during the 10 years. And in the rest 29 regions, only 4 ones have higher average scores than nation total mean, such as Beijing, Jiangsu, Fujiang, and Shandong. Accordingly the other 25 regions have the lower scores.

As the previous analyses, we divide the 29 inefficient provincial regions into 3 groups. The first group contains regions where the arithmetic mean of SE is lower than 0.8. It involves Inner Mongolia, Gansu, Qinghai, Ningxia. Additionally, the secondly group contains regions where the arithmetic mean of SE is in the internal of $(0.8,0.9)$. It involves Jilin, Anhui, Hainan, Guizhou, Tibet. Lastly, the rest 20 regions have the scores higher than 0.9. Compared with the TE and PTE score of intensive use of construction land in China and each region over the 10 years, the SE score is the most positive one.

In another aspect, the return to scale of intensive use of construction land in China is stable over the 10 years. In the 31 provincial regions of the 10 years, Heilongjiang and Shanghai maintain constant returns to scale. Inner Mongolia, Jilin, Anhui, Hunan, Guangxi, Sichuan, Guizhou, Yunnan, Gansu, Qinghai, Ningxia, keep returns of scale continuous increasing. Only Zhejiang keeps returns of scale decreasing. And the returns to scale of the other 17 regions change irregularly. 


\section{Conclusion and Suggestion}

Based on Data Envelopment Analysis, we get the technological efficiency (TE), pure technological efficiency (PTE), and scale efficiency (SE) of intensive use of construction land in China and each provincial region from 1999 to 2008. For the 10 years of data, the average TE score, PTE score, and SE score of national total are respectively equal to $0.768,0.781$, and 0.984 . Notably, the average SE score is much higher than the average PTE score. It indicates that the inefficiency of intensive use of Chinese construction land is mainly because of the inefficiency of PTE. Therefore, in order to raise the DEA efficiency of intensive use of Chinese construction land, we should enhance the PTEs of China and each provincial region. In the mean time, the PTEs of most provincial regions are higher than that of national total. Thus to increase the PTEs of other areas excluding provincial regions is the key to improve national total PTE.

What is more, to better analyze the results, we divide 31 provincial regions into 3 groups according to their locations. The first group is the eastern area of China, in which the average TE score is 0.863 . And the second group is the middle area of China, in which the average TE score is 0.722 . Finally, the third group is the western area of China, in which the average TE score is 0.642 . Apparently, eastern area has the highest score and western area has the lowest score. So augmenting the TE of the mid-western area of China is one of the best effective ways to enhance the TE of the nation.

From 1999 to 2008, both the inputs and outputs of construction land in each provincial region have augmented. However, the proportions of each element in mainly provincial regions are various and unreasonable. That is a primary reason of inefficiency of intensive use of Chinese construction land. In the 10 years, only Heilongjiang and Shanghai are DEA efficient. Thus, in order to obtain more output, they must enlarge the input scale according to the previous proportions of element. In addition, Xinjiang has been pure technological efficient during the 10 years. So what it needs is just to improve its scale efficiency. For the other provincial regions, government should help them adjust their input scale of construction land for the sake of the best proportion of input and output. If these suggestions will be accepted by Chinese government, we believe that the intensive use of Chinese construction land will be more effective in the future.

\section{References}

Baker, R. D. (1984). Estimating most productive scale size using data envelopment analysis. European Journal of Operational Research, 1, 35-44. http://dx.doi.org/10.1016/0377-2217(84)90006-7

Banker, R. D., Charnes, A. \& Cooper, W. W. (1984). Some models for estimating technical and scale inefficiencies in data envelopment analysis. Management Science, 3, 1078-1092. http://dx.doi.org/10.1287/mnsc.30.9.1078

Denison, E. F. (1962). The sources of economic growth in the United States and the alternative before us. Brookings Institution.

Charnes, A., Cooper, W. W., \& Rhodes, E. (1978). Measuring the efficiency of decision making units. European Journal of Operational Research, 2, 429-444. http://dx.doi.org/10.1016/0377-2217(78)90138-8

Farrell, M. J. (1957). The measurement of productive efficiency. Journal of the Royal Statistical Society, 120, 253-281. http://dx.doi.org/10.2307/2343100

Fare, R. S., Grosskopf, C. A., \& Lovell, K. (1994). Production frontiers. Cambridge University Press.

Li, Xun, Xu, Xianxiang, \& Chen, Haohui. (2005). Temporal and spatial changes of urban efficiency in the 1990s. ACTA Geographica Sinica, 60(4), 615-625.

Li, Chunhua, Li, Ning, Wu, Lichao, \& Shi, Hao. (2011). Efficiency Evaluation and Path Optimization of Land Intensive Use in Changsha City Based on Data Envelopment Analysis Model. Chinese Agricultural Science Bulletin, 27(01), 313-317.

Song, Ge, \& Gao, Nan. (2008). Economic Benefit Analysis of Urban Land Utilization Based on DEA Method-A Case of Harbin City. Scientia Geographica Sinica, 28(2), 185-188.

Tian, Chun, \& Li, Shiping. (2009). Urban land use relative efficiency in Shanxi based on DEA. Territory and Natural Resources Study, 1, 43-44.

Wang, Wanmao, \& Han, Tonggui. (2002). Land use planning. Beijing: China Agriculture Press.

Wei, Quanling. (2006). Data envelopment analysis. Beijing: China Science Press.

Zhang, Weili, Han, E, \& Ye, Minqiang. (2005). Validity analysis of economic input and output in Yangtze River Delta. Inquiry into Economic Issue, 7, 16-19. 
Table 1. TE of intensive use of construction land from 1999 to 2008

\begin{tabular}{|c|c|c|c|c|c|c|c|c|c|c|c|}
\hline$\underset{\text { region }}{\text { year }}$ & 1999 & 2000 & 2001 & 2002 & 2003 & 2004 & 2005 & 2006 & 2007 & 2008 & mean \\
\hline National total & 0.780 & 0.823 & 0.849 & 0.798 & 0.772 & 0.795 & 0.673 & 0.750 & 0.706 & 0.734 & 0.768 \\
\hline Beijing & 0.959 & 0.930 & 0.920 & 0.869 & 0.813 & 0.933 & 1.000 & 1.000 & 1.000 & 1.000 & 0.942 \\
\hline Tianjing & 0.953 & 0.960 & 0.924 & 0.908 & 0.865 & 0.923 & 1.000 & 1.000 & 1.000 & 1.000 & 0.953 \\
\hline Hebei & 0.711 & 0.730 & 0.795 & 0.806 & 0.806 & 0.816 & 0.850 & 0.805 & 0.829 & 0.822 & 0.797 \\
\hline Shanxi & 0.834 & 0.840 & 0.796 & 0.725 & 0.642 & 0.603 & 0.747 & 0.752 & 0.837 & 0.959 & 0.774 \\
\hline $\begin{array}{l}\text { Inner } \\
\text { Mongolia }\end{array}$ & 0.832 & 0.826 & 0.800 & 0.709 & 0.569 & 0.577 & 0.547 & 0.543 & 0.602 & 0.631 & 0.664 \\
\hline Jiaoning & 1.000 & 1.000 & 1.000 & 1.000 & 0.939 & 0.804 & 0.691 & 0.641 & 0.668 & 0.713 & 0.846 \\
\hline Jilin & 0.779 & 0.737 & 0.760 & 0.758 & 0.770 & 0.789 & 0.673 & 0.599 & 0.664 & 0.636 & 0.717 \\
\hline Heilongjiang & 1.000 & 1.000 & 1.000 & 1.000 & 1.000 & 1.000 & 1.000 & 1.000 & 1.000 & 1.000 & 1.000 \\
\hline Shanghai & 1.000 & 1.000 & 1.000 & 1.000 & 1.000 & 1.000 & 1.000 & 1.000 & 1.000 & 1.000 & 1.000 \\
\hline Jiangsu & 1.000 & 0.975 & 0.997 & 0.961 & 0.844 & 0.853 & 0.870 & 0.843 & 0.788 & 0.738 & 0.887 \\
\hline Zhejiang & 0.923 & 0.785 & 0.751 & 0.734 & 0.682 & 0.689 & 0.752 & 0.750 & 0.815 & 0.872 & 0.775 \\
\hline Anhui & 0.891 & 0.874 & 0.881 & 0.816 & 0.778 & 0.740 & 0.652 & 0.537 & 0.453 & 0.431 & 0.705 \\
\hline Fujian & 0.991 & 1.000 & 1.000 & 1.000 & 1.000 & 1.000 & 0.822 & 0.754 & 0.694 & 0.659 & 0.892 \\
\hline Jiangxi & 1.000 & 1.000 & 0.971 & 0.765 & 0.659 & 0.662 & 0.551 & 0.517 & 0.507 & 0.432 & 0.706 \\
\hline Shandong & 0.948 & 0.929 & 0.953 & 0.869 & 0.736 & 0.738 & 0.750 & 0.756 & 0.812 & 0.798 & 0.829 \\
\hline Henan & 0.829 & 0.866 & 0.888 & 0.859 & 0.797 & 0.795 & 0.674 & 0.645 & 0.672 & 0.691 & 0.772 \\
\hline Hubei & 0.851 & 0.857 & 0.870 & 0.868 & 0.883 & 0.887 & 0.773 & 0.738 & 0.669 & 0.620 & 0.802 \\
\hline Hunan & 0.900 & 0.951 & 0.947 & 0.891 & 0.930 & 0.944 & 0.782 & 0.774 & 0.710 & 0.667 & 0.850 \\
\hline Guangdong & 0.903 & 0.905 & 0.921 & 0.905 & 0.833 & 0.840 & 1.000 & 1.000 & 1.000 & 1.000 & 0.931 \\
\hline Guangxi & 0.828 & 0.874 & 0.959 & 0.881 & 0.850 & 0.816 & 0.717 & 0.634 & 0.556 & 0.513 & 0.763 \\
\hline Hainan & 1.000 & 1.000 & 0.981 & 1.000 & 0.911 & 0.956 & 0.774 & 0.783 & 0.772 & 0.592 & 0.877 \\
\hline Chongqing & 0.755 & 0.780 & 0.758 & 0.673 & 0.654 & 0.616 & 0.536 & 0.501 & 0.442 & 0.430 & 0.615 \\
\hline Sichuan & 0.681 & 0.662 & 0.725 & 0.671 & 0.663 & 0.755 & 0.618 & 0.594 & 0.537 & 0.549 & 0.646 \\
\hline Guizhou & 0.618 & 0.578 & 0.496 & 0.472 & 0.484 & 0.522 & 0.575 & 0.560 & 0.548 & 0.561 & 0.541 \\
\hline Yunnan & 0.803 & 0.768 & 0.785 & 0.788 & 0.745 & 0.749 & 0.690 & 0.674 & 0.685 & 0.679 & 0.737 \\
\hline Tibet & 1.000 & 0.939 & 0.917 & 1.000 & 0.759 & 0.708 & 0.507 & 0.468 & 0.475 & 0.443 & 0.722 \\
\hline Shaanxi & 0.650 & 0.694 & 0.713 & 0.667 & 0.665 & 0.664 & 0.658 & 0.656 & 0.631 & 0.609 & 0.661 \\
\hline Gansu & 0.628 & 0.645 & 0.633 & 0.622 & 0.617 & 0.648 & 0.744 & 0.792 & 0.784 & 0.735 & 0.685 \\
\hline Qinghai & 0.697 & 0.603 & 0.535 & 0.537 & 0.544 & 0.557 & 0.508 & 0.510 & 0.543 & 0.566 & 0.560 \\
\hline Ningxia & 0.528 & 0.472 & 0.458 & 0.443 & 0.385 & 0.398 & 0.485 & 0.502 & 0.507 & 0.474 & 0.465 \\
\hline Xinjiang & 0.824 & 0.879 & 0.873 & 0.900 & 0.935 & 0.975 & 0.931 & 1.000 & 1.000 & 1.000 & 0.932 \\
\hline
\end{tabular}


Table 2. PTE of intensive use of construction land from 1999 to 2008

\begin{tabular}{|c|c|c|c|c|c|c|c|c|c|c|c|}
\hline$\underset{\text { region }}{\text { year }}$ & 1999 & 2000 & 2001 & 2002 & 2003 & 2004 & 2005 & 2006 & 2007 & 2008 & mean \\
\hline National total & 0.782 & 0.824 & 0.855 & 0.850 & 0.788 & 0.798 & 0.673 & 0.777 & 0.721 & 0.741 & 0.781 \\
\hline Beijing & 0.964 & 0.935 & 0.930 & 0.871 & 0.819 & 0.950 & 1.000 & 1.000 & 1.000 & 1.000 & 0.947 \\
\hline Tianjing & 0.967 & 0.980 & 0.952 & 0.956 & 0.988 & 1.000 & 1.000 & 1.000 & 1.000 & 1.000 & 0.984 \\
\hline Hebei & 0.712 & 0.730 & 0.795 & 0.809 & 0.813 & 0.821 & 0.852 & 0.820 & 0.859 & 0.859 & 0.807 \\
\hline Shanxi & 0.850 & 0.870 & 0.838 & 0.782 & 0.658 & 0.626 & 0.748 & 0.764 & 0.859 & 0.977 & 0.797 \\
\hline $\begin{array}{l}\text { Inner } \\
\text { Mongolia }\end{array}$ & 1.000 & 1.000 & 1.000 & 1.000 & 0.906 & 0.909 & 1.000 & 1.000 & 1.000 & 0.999 & 0.981 \\
\hline Jiaoning & 1.000 & 1.000 & 1.000 & 1.000 & 0.950 & 0.810 & 0.721 & 0.670 & 0.689 & 0.737 & 0.858 \\
\hline Jilin & 0.864 & 0.837 & 0.875 & 0.851 & 0.893 & 0.864 & 0.810 & 0.747 & 0.771 & 0.745 & 0.826 \\
\hline Heilongjiang & 1.000 & 1.000 & 1.000 & 1.000 & 1.000 & 1.000 & 1.000 & 1.000 & 1.000 & 1.000 & 1.000 \\
\hline Shanghai & 1.000 & 1.000 & 1.000 & 1.000 & 1.000 & 1.000 & 1.000 & 1.000 & 1.000 & 1.000 & 1.000 \\
\hline Jiangsu & 1.000 & 1.000 & 1.000 & 1.000 & 0.847 & 0.854 & 0.871 & 0.851 & 0.809 & 0.765 & 0.900 \\
\hline Zhejiang & 1.000 & 0.949 & 0.825 & 0.785 & 0.720 & 0.714 & 0.768 & 0.775 & 0.850 & 0.891 & 0.828 \\
\hline Anhui & 0.926 & 0.927 & 0.968 & 0.960 & 0.857 & 0.770 & 0.739 & 0.664 & 0.583 & 0.527 & 0.792 \\
\hline Fujian & 1.000 & 1.000 & 1.000 & 1.000 & 1.000 & 1.000 & 0.862 & 0.772 & 0.707 & 0.662 & 0.900 \\
\hline Jiangxi & 1.000 & 1.000 & 1.000 & 0.853 & 0.688 & 0.667 & 0.592 & 0.598 & 0.588 & 0.498 & 0.748 \\
\hline Shandong & 0.952 & 0.932 & 0.954 & 0.874 & 0.758 & 0.755 & 0.756 & 0.769 & 0.825 & 0.818 & 0.839 \\
\hline Henan & 0.838 & 0.880 & 0.916 & 0.900 & 0.820 & 0.800 & 0.690 & 0.658 & 0.680 & 0.693 & 0.788 \\
\hline Hubei & 0.863 & 0.860 & 0.870 & 0.870 & 0.896 & 0.890 & 0.796 & 0.795 & 0.768 & 0.716 & 0.832 \\
\hline Hunan & 0.901 & 0.954 & 0.968 & 0.980 & 0.971 & 0.953 & 0.819 & 0.854 & 0.808 & 0.740 & 0.895 \\
\hline Guangdong & 1.000 & 1.000 & 0.976 & 0.975 & 0.925 & 0.908 & 1.000 & 1.000 & 1.000 & 1.000 & 0.978 \\
\hline Guangxi & 0.861 & 0.893 & 0.998 & 1.000 & 0.899 & 0.824 & 0.783 & 0.716 & 0.674 & 0.623 & 0.827 \\
\hline Hainan & 1.000 & 1.000 & 1.000 & 1.000 & 1.000 & 1.000 & 1.000 & 1.000 & 1.000 & 0.928 & 0.993 \\
\hline Chongqing & 0.758 & 0.783 & 0.766 & 0.704 & 0.670 & 0.619 & 0.560 & 0.548 & 0.508 & 0.483 & 0.640 \\
\hline Sichuan & 0.688 & 0.675 & 0.749 & 0.748 & 0.697 & 0.763 & 0.666 & 0.665 & 0.634 & 0.640 & 0.693 \\
\hline Guizhou & 0.648 & 0.612 & 0.543 & 0.556 & 0.530 & 0.553 & 0.635 & 0.641 & 0.668 & 0.671 & 0.606 \\
\hline Yunnan & 0.825 & 0.801 & 0.817 & 0.814 & 0.768 & 0.760 & 0.718 & 0.705 & 0.723 & 0.711 & 0.764 \\
\hline Tibet & 1.000 & 1.000 & 1.000 & 1.000 & 0.835 & 0.817 & 0.691 & 0.648 & 0.627 & 0.615 & 0.823 \\
\hline Shaanxi & 0.679 & 0.720 & 0.753 & 0.756 & 0.692 & 0.670 & 0.666 & 0.660 & 0.639 & 0.615 & 0.685 \\
\hline Gansu & 0.763 & 0.790 & 0.804 & 0.931 & 1.000 & 1.000 & 1.000 & 1.000 & 1.000 & 0.993 & 0.928 \\
\hline Qinghai & 0.928 & 0.906 & 0.871 & 0.867 & 0.925 & 0.894 & 0.922 & 0.895 & 0.919 & 0.954 & 0.908 \\
\hline Ningxia & 0.632 & 0.610 & 0.601 & 0.595 & 0.544 & 0.540 & 0.641 & 0.669 & 0.661 & 0.648 & 0.614 \\
\hline Xinjiang & 1.000 & 1.000 & 1.000 & 1.000 & 1.000 & 1.000 & 1.000 & 1.000 & 1.000 & 1.000 & 1.000 \\
\hline
\end{tabular}


Table 3. SE of intensive use of construction land from 1999 to 2008

\begin{tabular}{|c|c|c|c|c|c|c|c|c|c|c|c|}
\hline$\underset{\text { region }}{\text { year }}$ & 1999 & 2000 & 2001 & 2002 & 2003 & 2004 & 2005 & 2006 & 2007 & 2008 & mean \\
\hline National total & 0.998 & 0.999 & 0.992 & 0.939 & 0.981 & 0.996 & 1.000 & 0.965 & 0.979 & 0.991 & 0.984 \\
\hline Beijing & 0.994 & 0.995 & 0.989 & 0.997 & 0.993 & 0.982 & 1.000 & 1.000 & 1.000 & 1.000 & 0.995 \\
\hline Tianjing & 0.986 & 0.980 & 0.971 & 0.950 & 0.875 & 0.923 & 1.000 & 1.000 & 1.000 & 1.000 & 0.969 \\
\hline Hebei & 0.999 & 1.000 & 1.000 & 0.997 & 0.991 & 0.993 & 0.998 & 0.982 & 0.966 & 0.957 & 0.988 \\
\hline Shanxi & 0.981 & 0.966 & 0.950 & 0.927 & 0.976 & 0.964 & 0.999 & 0.984 & 0.975 & 0.981 & 0.970 \\
\hline $\begin{array}{l}\text { Inner } \\
\text { Mongolia }\end{array}$ & 0.832 & 0.826 & 0.800 & 0.709 & 0.628 & 0.634 & 0.547 & 0.543 & 0.602 & 0.632 & 0.675 \\
\hline Jiaoning & 1.000 & 1.000 & 1.000 & 1.000 & 0.988 & 0.993 & 0.958 & 0.955 & 0.969 & 0.967 & 0.983 \\
\hline Jilin & 0.901 & 0.880 & 0.869 & 0.891 & 0.862 & 0.913 & 0.831 & 0.802 & 0.861 & 0.854 & 0.866 \\
\hline Heilongjiang & 1.000 & 1.000 & 1.000 & 1.000 & 1.000 & 1.000 & 1.000 & 1.000 & 1.000 & 1.000 & 1.000 \\
\hline Shanghai & 1.000 & 1.000 & 1.000 & 1.000 & 1.000 & 1.000 & 1.000 & 1.000 & 1.000 & 1.000 & 1.000 \\
\hline Jiangsu & 1.000 & 0.975 & 0.997 & 0.961 & 0.996 & 1.000 & 0.999 & 0.991 & 0.975 & 0.964 & 0.986 \\
\hline Zhejiang & 0.923 & 0.827 & 0.910 & 0.935 & 0.948 & 0.964 & 0.979 & 0.968 & 0.958 & 0.979 & 0.939 \\
\hline Anhui & 0.962 & 0.943 & 0.911 & 0.851 & 0.908 & 0.961 & 0.882 & 0.809 & 0.776 & 0.819 & 0.882 \\
\hline Fujian & 0.991 & 1.000 & 1.000 & 1.000 & 1.000 & 1.000 & 0.954 & 0.977 & 0.981 & 0.996 & 0.990 \\
\hline Jiangxi & 1.000 & 1.000 & 0.971 & 0.897 & 0.958 & 0.992 & 0.931 & 0.864 & 0.862 & 0.868 & 0.934 \\
\hline Shandong & 0.996 & 0.997 & 0.998 & 0.994 & 0.970 & 0.977 & 0.993 & 0.982 & 0.984 & 0.976 & 0.987 \\
\hline Henan & 0.989 & 0.984 & 0.970 & 0.954 & 0.973 & 0.994 & 0.978 & 0.980 & 0.987 & 0.997 & 0.981 \\
\hline Hubei & 0.986 & 0.996 & 1.000 & 0.998 & 0.985 & 0.996 & 0.972 & 0.928 & 0.871 & 0.865 & 0.960 \\
\hline Hunan & 0.998 & 0.997 & 0.978 & 0.909 & 0.958 & 0.991 & 0.955 & 0.907 & 0.879 & 0.902 & 0.947 \\
\hline Guangdong & 0.903 & 0.905 & 0.944 & 0.929 & 0.901 & 0.925 & 1.000 & 1.000 & 1.000 & 1.000 & 0.951 \\
\hline Guangxi & 0.961 & 0.979 & 0.961 & 0.881 & 0.946 & 0.990 & 0.915 & 0.885 & 0.825 & 0.823 & 0.917 \\
\hline Hainan & 1.000 & 1.000 & 0.981 & 1.000 & 0.911 & 0.956 & 0.774 & 0.783 & 0.772 & 0.638 & 0.882 \\
\hline Chongqing & 0.996 & 0.997 & 0.989 & 0.956 & 0.975 & 0.994 & 0.956 & 0.913 & 0.869 & 0.889 & 0.953 \\
\hline Sichuan & 0.989 & 0.982 & 0.968 & 0.897 & 0.952 & 0.990 & 0.928 & 0.893 & 0.847 & 0.858 & 0.930 \\
\hline Guizhou & 0.953 & 0.945 & 0.915 & 0.850 & 0.914 & 0.944 & 0.905 & 0.874 & 0.821 & 0.836 & 0.896 \\
\hline Yunnan & 0.974 & 0.958 & 0.961 & 0.968 & 0.970 & 0.986 & 0.961 & 0.956 & 0.948 & 0.954 & 0.964 \\
\hline Tibet & 1.000 & 0.939 & 0.917 & 1.000 & 0.909 & 0.867 & 0.734 & 0.722 & 0.758 & 0.721 & 0.857 \\
\hline Shaanxi & 0.956 & 0.964 & 0.947 & 0.882 & 0.962 & 0.992 & 0.987 & 0.993 & 0.987 & 0.990 & 0.966 \\
\hline Gansu & 0.823 & 0.817 & 0.788 & 0.668 & 0.617 & 0.648 & 0.744 & 0.792 & 0.784 & 0.740 & 0.742 \\
\hline Qinghai & 0.751 & 0.666 & 0.615 & 0.620 & 0.588 & 0.623 & 0.551 & 0.570 & 0.590 & 0.593 & 0.617 \\
\hline Ningxia & 0.835 & 0.774 & 0.763 & 0.745 & 0.708 & 0.737 & 0.756 & 0.751 & 0.766 & 0.732 & 0.757 \\
\hline Xinjiang & 0.824 & 0.879 & 0.873 & 0.900 & 0.935 & 0.975 & 0.931 & 1.000 & 1.000 & 1.000 & 0.932 \\
\hline
\end{tabular}




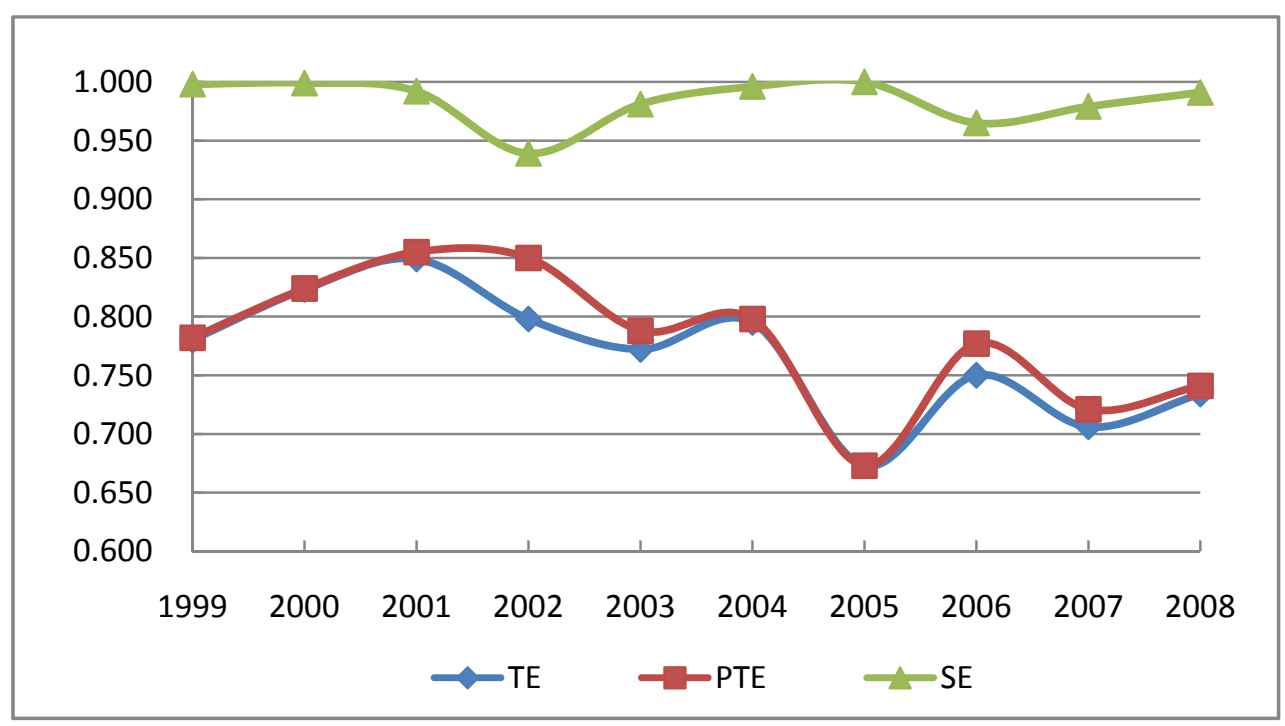

Figure 1. Variation of national total TE, PTE, SE from 1999 to 2008 